\title{
Rethinking Lunar Mare Basalt Regolith Formation: New Concepts of Lava Flow Protolith
} and Evolution of Regolith Thickness and Internal Structure

\author{
James W. Head ${ }^{1}$ and Lionel Wilson ${ }^{2,1}$ \\ ${ }^{1}$ Department of Earth, Environmental and Planetary Science, \\ Brown University, Providence, Rhode Island 02912 USA. \\ ${ }^{2}$ Lancaster Environment Centre, Lancaster University, Lancaster LA1 4YQ UK \\ Submitted to Geophysical Research Letters \\ \#2020GL088334 \\ April 9, 2020 \\ Revised September 21, 2020
}

\begin{abstract}
Lunar mare regolith is traditionally thought to have formed by impact bombardment of newly emplaced coherent solidified basaltic lava. We use new models for initial emplacement of basalt magma to predict and map out thicknesses, surface topographies and internal structures of the fresh lava flows and pyroclastic deposits that form the lunar mare regolith parent rock, or protolith. The range of basaltic eruption types produce widely varying initial conditions for regolith protolith, including 1) "auto-regolith", a fragmental meters-thick surface deposit that forms upon eruption and mimics impact-generated regolith in physical properties, 2) lava flows with significant near-surface vesicularity and macro-porosity, 3) magmatic foams, and 4) dense, vesicle-poor flows. Each protolith has important implications for the subsequent growth, maturation and regional variability of regolith deposits, suggesting wide spatial variations in the properties and thickness of regolith of similar age. Regolith may thus provide key insights into mare basalt protolith and its mode of emplacement.

Plain Language Summary: Following recent studies of how lava eruptions are emplaced on the lunar surface, we show that solid basalt is only one of a wide range of starting conditions in the process of forming lunar soil (regolith). Gas present in the lavas during eruption also produced bubbles, foams and explosive products, disrupting the lava and forming other starting conditions for mare soil parent material.
\end{abstract}




\section{Introduction and Background}

In contrast to Earth, where water-rock interactions cause soil formation to be dominantly a chemical weathering process, high-energy physical weathering processes dominate the formation and evolution of the lunar regolith (Hörz, 1977): 1) micrometeorite comminution (rock breakup into smaller fragments), and 2) agglutination (quenched impact glass and welded particles averaging 25-30 vol\% of regolith) (McKay et al., 1974). The canonical model for lunar mare regolith development (e.g., Hörz, 1977; Langevin and Arnold, 1977; McKay et al., 1991; Lucey et al., 2006) begins with the emplacement of a lava flow, representing a fresh solid basalt surface unaffected by impact bombardment or space weathering processes (Wilcox et al., 2005). The pristine surface and interior of the new lava flow (Fig. 1) is the mare regolith parent rock, or protolith, and is generally thought of as being dense, solidified basalt. Because the fresh surface of a lunar lava flow has never been observed, most regolith development models assume a generally flat lava flow surface and a solid coherent flow interior. The apparent lack of significant volatiles such as $\mathrm{H}_{2} \mathrm{O}$ in lunar magmas led to earlier assumptions that most mare basalt flows would be essentially non-vesicular.

Regolith formation begins with impact bombardment onto the pristine dense lava flow, a stochastic process that deforms, pulverizes, melts and ejects basalt protolith to become the initial stages of the regolith layer, in stark contrast to the characteristics of evolved or more mature regolith (Fig. 1). Two major temporal trends occur in regolith development: 1) buffering trend: the initial predominantly coarse-grained and blocky substrate ejecta from the protolith becomes subject to further impact bombardment at all scales (particularly micro-meteorite), comminuting blocks, reducing grain size, overturning soil grains and exposing them to space weathering/solar wind, adding more and more agglutinates to the soil, and reworking alreadyexisting regolith material. The growing regolith layer thus acts as a buffer to further regolith growth, favoring reworking over further breakup of the protolith. 2) impact flux trend: decreasing impact flux during the several Ga period of mare basalt emplacement means that the rate of bombardment of older flows, and the rate of regolith growth, will be non-linear; younger lava flows will be subject to a lower integrated impact flux and lower absolute flux. These general trends result in a paradigm of regolith development constructed from observations and data from orbital, Apollo and Luna surface observations, soil mechanics experiments, and detailed laboratory analysis of regolith cores and returned samples (McKay et al., 1991; Lucey et al., 2006).

Four recent developments have the potential to change this paradigm. First, discoveries in the last decade have pointed to the presence of significant amounts of $\mathrm{H}_{2} \mathrm{O}$ and other volatile species in lunar magmas (Saal et al., 2008; Hauri et al., 2011), and clarified their influence on the characteristics of ascending magma (Rutherford et al., 2017). Secondly, improved models of the generation, ascent and eruption of mare basalt magma (Wilson and Head 2017a; 2018), including updated inclusion of magmatic volatiles, have underlined the distinctly different stages and associated deposits in the eruption and emplacement of mare basalts, including proximal pyroclastic deposits and distal lava flows (Head and Wilson, 2017; Wilson and Head, 2018; Garry et al., 2012). Third, global orbital remote sensing data (imaging, altimetry, radar, radiometry, thermal inertia, etc.) and Earth-based radar data have revealed significant diversity in the characteristics of mare volcanic landforms (Tables S1-S2), impact crater populations and 
morphologies, mare regolith surfaces, and mare subsurface materials (Lucey et al., 2006), all suggesting that regolith properties are likely to be much more diverse than the paradigm developed from Apollo and Luna sites. Finally, renewed interest in human and robotic lunar exploration, and thus resource/geotechnical/engineering aspects of a more sustained human presence, have encouraged global characterization of the mare regolith layer and its underlying mare basalt protolith. In this analysis, we review developments in understanding the stages in the ascent and eruption of magma for new insights into the production of lunar mare regolith protolith, and the implications for regolith development, and its global characteristics and variability (Tables S1-S2).

\section{Lunar Mare Basalt Lava Flow Emplacement Paradigm}

Assessment of gas release patterns (Rutherford et al., 2017) during individual mare basalt eruptions (Wilson and Head, 2018) provides the basis for predicting the effect of vesiculation processes on the structure and morphology of eruption products: typical lunar eruptions are subdivided into four phases (Fig. 2a). These phases, controlled by total dike volumes, initial magma volatile content, vent configuration, and magma discharge rate, define the wide range of initial mare basalt extrusive products and consequent regolith protoliths produced in space and time (Table S1).

The rising dike penetrates the surface initiating Phase 1, the minutes-long, explosive transient gas release phase due to volatile concentration into the low-pressure upwardpropagating dike tip; this results in a very widespread but extremely thin deposit, distributing the ubiquitous volcanic glass beads found in lunar soils (Heiken and McKay, 1974; Heiken, 1975; Delano, 1986). The dike continues to rise toward a neutral buoyancy configuration, initiating the high-flux hawaiian eruptive Phase 2, characterized by peak magma discharge rates, the near-steady explosive eruption of magma containing bulk volatile content, and formation of a relatively steady, largely optically-dense hawaiian fire fountain. Pyroclasts lose gas efficiently and accumulate within $\sim 10 \mathrm{~km}$ of the fissure, forming a lava lake deficient in gas bubbles. In short-lived eruptions, degassed lava flows away from the lake to form the distal parts of a dense lava flow. In long-lasting eruptions, lava erodes a sinuous rille. Phase 2 involves eruption of a significant part of the total dike magma volume and magma volume flux decreases with time (Fig. 2a).

When the dike approaches an equilibrium, the vertical extent of the dike becomes fixed, and a rapid change occurs toward the lower-flux Phase 3 hawaiian to strombolian transition. The main driving process is the horizontal reduction in the dike thickness due to a decrease in internal excess pressure and relaxation of dike intrusion-induced deformation. Magma vertical rise speed decreases greatly to less than $1 \mathrm{~m} / \mathrm{s}$; magma volume flux leaving the vent decreases to a few $\times 10^{4} \mathrm{~m}^{3} \mathrm{~s}^{-1}$ over $\sim 3-5$ days. These reductions mean that $\mathrm{CO}$ gas bubbles nucleating deep in the dike can now rise significantly through their parent liquid, with larger bubbles overtaking smaller bubbles, leading to coalescence, greater growth, and eventual formation of gas slugs filling almost the entire dike width and producing surface strombolian explosions (e.g., Keske et al., 2020).

When vent activity becomes entirely strombolian the dike closing, strombolian vesicular flow Phase 4 begins; horizontal dike closure continues, and magma is extruded at a low flux. Minor strombolian explosive activity continues; rise rates are sufficiently low that a stable crust 
will form on magma in the lava lake and flowing away as lava flows. In a low-flux eruption, Phase 4 begins only after most of magma in the dike has been erupted and the volume flux is at a very low level, resulting in the emplacement of vesicular lava in the vent vicinity (Fig. 2a,b). Erupted magma consists of lava containing bubbles of a mixture of gases and volatile elements (Gaillard \& Scaillet, 2014; Renggli et al., 2017). Lavas exsolving 1,000 ppm of these gases would leave the vent as lava foams with vesicularities $>90 \%$ by volume. The topmost bubbles would explode into the overlying vacuum, producing a bubble wall shard layer (an "auto-regolith") (Qiao et al., 2020, their Fig. 14); gas would escape through this accumulating debris layer until welding and the accumulated debris weight inhibited further foam disintegration. If the underlying lava still contained dissolved volatiles, volatile concentration into the remaining liquid as the lava cooled and crystallized would result in second boiling (an increase in vapor pressure to the point of supersaturation) and additional post-emplacement vesiculation, causing a range of macro-micro-vesicularity (Wilson et al., 2019, their Fig. 5). In a high-flux eruption Phase 4 (somewhat higher than $10^{4} \mathrm{~m}^{3} \mathrm{~s}^{-1}$ ), a large fraction of the total dike volume is still available for extrusion as vesicular lava (Fig. 2a). This lava is predicted to cause flow inflation (Self et al, 1996; Hamilton et al., 2020), intruding vesicular lava into the still-hot interiors of the previously emplaced non-vesicular flows. Magma from the shallow parts of the dike $(<400 \mathrm{~m}$ ) feeding such intruding flows would contain water/sulfur compounds that had not yet exsolved. As the resulting inflated flows cooled on a timescale of weeks, second boiling would occur in this case also, causing a further, possibly extensive, inflation episode (Wilson et al., 2019; their Fig. 5). For eruptions contained within summit pit craters, Phase 4 lavas can pond and undergo further distinctive protolith evolution (Fig. 2c)

We now explore the implications of these four phases of a typical mare basalt eruption (Fig. 2a) for the resulting surface deposits, the mare basalt regolith protolith.

\section{Mare Basalt Protolith Types: Implications for Regolith Evolution}

What are the major different types of surface topography, morphology, surface properties, and internal structure (Fig. 3) of deposits predicted by these four phases (P1-P4), (Figs. 2,3), their distribution (Table S1), and the implications for regolith development on these protoliths?

1. Solidified Non-Vesicular Coherent Mare Basalt: Magma largely degassed at the vent during the hawaiian activity of $\mathrm{P} 2$ will produce several-100 km long, generally flat, smoothsurfaced flows, with low vesicularity, that cool to solidified basalts up to tens of $m$ thick (Fig. 3a). Their distribution and plan view will be influenced by surface topography underlying the flow, regional slopes, and flow cooling behavior (Head and Wilson, 2017). Distal flows associated with sinuous rilles should also form this type of regolith protolith. These flows should be very widespread distally from the vent and form a regolith protolith that is similar to that of the standard regolith evolution model (Fig. 1; Table S1).

2. Inflated Flows: Surface Topography, Vesicularity and Meso-Macro Porosity: If P4 activity is of long duration, flow inflation of P2 flows can result, elevating and distorting the pre-existing solidified flow surface, and introducing several-m scale topographic irregularities on the recently solidified upper thermal boundary layer of the flow (Fig. 3b). This extremely irregular protolith surface (e.g., Hamilton et al., 2020) will influence the nature of initial stages of regolith development, causing irregular crater formation and ejecta distribution at scales less than the average roughness. The solidified inflated core of the flow at depths of a few meters will 
consist of a very porous layer of low-density vesicular basalt of significant thickness due to intrusion of very vesicular P3 magma. Furthermore, meter-scale void spaces from coalescence of vertically migrating gas pockets are also predicted (Wilson et al., 2019, their Fig. 5). As superposed craters are formed on this protolith, energy partitioning will favor crushing of vesicles and voids over brittle deformation and this will influence the grain size and shape of the initial regolith layers; meso- and macro-porosity will favor collapse pit and collapse crater formation, regolith drainage into void spaces, and slowing of optical maturation due to preferential drainage of the finest fractions. These inflated flows should be distributed closer to the vent than those formed from the non-inflated distal P2 flows (Table S1).

3. Inflated Flows: Second Boiling, Vertical Bubble Migration and Extrusion of Magmatic Foam: Prior to solidification, further cooling and evolution of P4-inflated P2 flows can cause second boiling and in situ generation of additional vesicular layers (Fig. 3c). If second boiling is significant (e.g., thick inflated layer, volatile-rich magma), bubble layers can undergo active upward migration of foams in pipes to form shallow gas pockets creating shallow meter-scale void space and further deforming the lava flow surface (Wilson et al., 2019, their Fig. 5). Theory further predicts that cracking of the upper thermal boundary layer can enable extrusion of foams potentially forming the small mounds known as Ring-Moat Dome Structures (RMDS) (Zhang et al., 2017, 2020). Instead of the dense, vesicle-poor solidified basalt substrate (Figs. $1,3 a)$, much of the initial substrate will consist of an irregular surface and micro-, meso- and macro-porous protolith (also having undergone auto-regolith formation) in which impact energy partitioning will favor crushing of vesicles and voids, initially finer-grained regolith, and potential slowing of maturation due to drainage of the finest fraction into the still-porous substrate. The presence of surface magmatic foams will favor crushing, changes in crater morphometry (vertical growth favored over lateral) and clast size fractions dominated by bubble-wall geometry (Morgan et al., 2019). The presence of unusual foam mounds (RMDS) might signal the locations of P4 inflated flows where significant second boiling has taken place (Table S2). These inflated flows should be distributed closer to the vent than those formed from the non-inflated distal P2 flows (Table S1).

4. Foam Flows and "Auto-Regolith" Formation: Some very vesicular P4 flows can extrude out onto the surface near the vent (Fig. $3 \mathrm{~d}$ ). When such highly vesicular flows are exposed to the lunar vacuum, they undergo catastrophic fragmentation and disruption that can destroy the entire meters-thick flow, leading to production of a fragmental layer (an auto-regolith); this auto-regolith layer can comprise the entire flow-unit thickness in a point-source eruption, and a significant amount of the flow thickness in fissure flows (Fig. 2b). Wilson et al. (2019; their Fig. 5) have described the process in detail; the resulting protolith stratigraphy of the cooled and solidified flow consists of an upper meters-thick fragmental layer of glassy shards (the "autoregolith") overlying a thin layer of welded pyroclasts, above an extremely vesicular layer up to several meters thick (Fig. 3d) (Table S1). Initial impacts will crush, comminute and redistribute this substrate, influencing initial crater formation and shape, and subsequent degradation; blocks derived from these layers will be rare and easily degraded.

5. Foam Flows With Coherent Surfaces: Some P4 flows can develop a coherent upper thermal boundary layer, inhibiting initial catastrophic foam flow disruption and resulting in extremely vesicular, low density meters-thick flows with a solidified carapace, and perhaps some initial collapse pits (Fig. 3e). These are most likely to occur in the vicinity of vents and pit 
craters, where variations in effusion rates can cause a solid crust to form and foam buildup below, before renewed activity extrudes it out of the vent area. This regolith protolith is predicted to have extremely high meso-macro-porosity, and initial impacts are likely to cause collapse and deformation of the substrate; the late-stage lava flows on the rim of the small shield volcano Cauchy 5 have been interpreted to display such a regolith protolith (Qiao et al, 2020) (Table S1).

6. Pyroclastic Layers: During P2, sustained hawaiian eruptive activity in the lunar vacuum results in regions surrounding the vent accumulating significant thicknesses (up to many 10s of $\mathrm{m}$ ) of pyroclastic beads out to ranges of several tens of km; Weitz et al., 1998; Gaddis et al., 2003 (Fig. 3f). The presence of such layers affects subsequent impact crater energy partitioning, crater size-frequency distributions, soil maturation, etc. The pyroclastic layers are a type of "auto-regolith" and can be interbedded with more coherent basaltic flow layers. Such a substrate was explored on Apollo 17, where the 120 m diameter Shorty crater had penetrated both pyroclastic and basalt flow layers (Schmitt, 1973) (Table S1).

7. Emplacement of Anomalous "Xenolithic" Volcanic Glass Beads: In the initial minutes of an eruption (P1) extremely explosive venting of gas and disrupted foam disperses pyroclasts very widely, well beyond the associated subsequent flow deposits (P2-4) (Fig. 3g). On the basis of the nature of the rapid gas expansion and pyroclast fragmentation, these pyroclasts should arrive at the target site as generally solidified round glass beads (Table S1). These are a candidate source of "xenolithic" pyroclasts in all regolith deposits (Delano, 1986). The highenergy of this venting can also incorporate and widely disperse pre-existing regolith particles from the venting site.

8. Volcanic Pit Crater Floor Surfaces: If P3 occurs in a pit or collapse crater (Fig. 2C) rather than a fissure eruption (Fig. 2b), P3 activity can concentrate strombolian pyroclasts and P4 foamy lavas in the depression, resulting in the development of an extremely high concentration of volatiles and magmatic foams below a solidified and evolving thermal boundary layer of unusual micro- and macro-vesicularity (Fig. 3h) (Table S1). The flexing and disruption of the highly macro-vesicular lava lake crust layer has been proposed to cause extrusion of magmatic foams to form mounds (Fig. 2c) (e.g., Wilson and Head, 2017b; Qiao et al. 2017, 2018, 2019, 2020). On the basis of the predicted properties of such a lava lake environment, these authors outlined solidified lava lake and magmatic mound substrate characteristics producing extremely underdense targets and potential regolith drainage. These characteristics could have significant implications for the nature and retention of superposed craters, the original and long-term regolith grain-size evolution, the slowing of optical maturation rates, and the retardation of aging interpreted from impact crater size-frequency distribution data.

\section{Discussion}

A. Summary of New Perspectives on Regolith Protolith Development:

Analysis of the phases of individual mare basalt eruptions (Fig. 2) provides a forward-model of the formation of regolith protolith and shows that the traditional view of a solid basaltic regolith protolith (Fig. 1) is only one of a wide array of regolith protoliths (Fig. 3). These results provide an interpretative framework to revisit and expand our understanding of mare basalt regolith-forming processes, and predictions for the interpretation of remote sensing data (Table S2). They also yield some potential new insights that might help clarify existing knowledge of 
regolith characteristics, and can be used to plan for future robotic and human scientific and resource exploration (Table S1).

B. Application of Protolith Concepts to Regolith Formation and Evolution:

1) Basal regolith-substrate interfaces: The starting conditions for regolith development (Fig. 3) can vary widely from solid basalt to a meters-thick "auto-regolith"; initial topography can vary up to tens of meters. These factors can significantly influence estimates of local and regional thickness and lateral continuity of regolith.

2) Energy partitioning in regolith-forming impact events: Efficiency of cratering will vary as a function of protolith surface and subsurface structure (Fig. 3). The ratio of rock substrate crushing/deformation to ejection will vary in space/time for substrates with meso-macroporosity, and grain sizes and shapes will vary accordingly. Initial development of an "autoregolith" will mean that impact "regolith buffering" will operate from the beginning. Different substrate responses to impact energy partitioning will introduce significant variability in regolith grain sizes, shapes, percentage agglutinates, presence/abundance of rocks, and thickness.

3) Morphology of fresh superposed impact craters: These should differ widely in early protolith bombardment on the basis of energy partitioning in different substrates (Fig. 3); this will cause sequential morphological differences as regolith thickens between and within flows. The normal fresh-crater morphological sequence employed to predict regolith thickness (Quaide and Oberbeck, 1968) in traditional substrates (Fig. 1) should be updated to include other protoliths (Fig. 3).

4) Regolith thickness with age: Regolith thickness/age relationships (e.g., Quaide and Oberbeck, 1968; Shkuratov and Bondarenko, 2001; Wilcox et al., 2005; Bart et al., 2011; Bart, 2014; Di et al., 2016) should take into account the nature of the initial substrate topography, structure (vertical and horizontal) and the potential presence of an auto-regolith (Fig. 3); great thickness variability in space and time is likely across this spectrum.

5) Regolith growth rates: "Auto-regolith" formation can provide both an initial multimeters-thick "regolith" layer and a buffering layer influencing regolith growth rates. Existing models of regolith growth rates (Xie et al., 2018) can be augmented with assessments based on the predicted range of regolith protoliths (Fig. 3).

6) Regolith components and maturation rates: Expected diversity of initial protolith conditions will map out into the relative proportions of components (e.g., indigenous and xenolithic pyroclastic glass, glass shards, grain vesicularity, grain sizes and shapes, mesostastis, etc.) in evolving regolith. An understanding of the full range of regolith protoliths (Fig. 3) can help interpretation of variations in these factors in current regolith samples and make testable predictions for future exploration (Tables S1-S2).

7) Degradation of superposed craters with time: Energy partitioning in different substrates (Fig. 3) will yield different initial crater morphologies and morphometries, influencing the interpretation of crater degradation and lifetime; very porous macro-vesicular substrates can also produce initial and subsequent collapse craters that can mimic degraded primary impacts. Landform and crater degradation analyses (e.g., Fassett and Thomson, 2014) can now employ the wider range of regolith protoliths (Fig. 3) to assess their implications.

8) Impact crater size-frequency distribution measurements and surface ages: Variable protolith characteristics in space/time result in variable superposed crater energy partitioning 
that can influence fresh and degraded impact crater morphology/morphometry, CSFD measurements, and determination of population equilibrium diameters. An extreme case of these types of effects is predicted to occur in pit crater floors (P3-4; Fig 2c) (e.g., Irregular Mare Patch mounds and hummocky terrain in Ina; Garry et al., 2012; Qiao et al., 2019; Wilson and Head, 2017b) where protolith variability (Figs. 2c,3) may have profound effects on superposed crater formation, retention, degradation, and CSFD.

9) Vertical structure of lava flows: Individual lava flow cross-sectional vertical structure should vary widely (in both space and time) (Fig. 3), in contrast to the dense solid basalt cooling unit commonly assumed (Fig. 1). Despite this diversity and complexity, eruption phase parameter space (Fig. 2a) offers promise to unravel the eruption history of individual crosssection exposures of intercalated lava flows and regolith layers (Kerber et al., 2019).

10) Variation in regolith protolith (Fig. 3) in space and time: In individual basaltic eruptions, protolith diversity and complexity is predicted to decrease as a function of distance from the eruptive vent (Fig. 2a) and, with the exception of P4 inflated flows, distal flows may be most similar to the traditional model (Fig. 1). Magmatic volatile abundances introduce additional variability in the nature of different eruptive stages and deposits; increasing insights into species and abundances (Rutherford et al., 2017) can be readily mapped into modified protolith paradigms. Improved models of eruption conditions, and deposit formation as a function of distance from the vent, will help to place point samples (e.g., Apollo 15 highly vesicular basalts, green pyroclastic glass beads; Apollo 17 orange/black pyroclastic glass beads) into more robust predictions for proximity to the eruptive vent and, together with remote sensing data, provide regional assessments of protolith trends. Exploration of vertical sections in impact and pit crater walls can provide insight into temporal variations in regolith protolith (Kerber et al., 2019).

\section{Conclusions and Implications}

On the basis of our forward-modeling of the four stages in lunar lava flow emplacement (Fig. 2a), we conclude that a wide diversity of regolith protoliths is likely to be present in lunar mare regolith deposits in addition to the traditional solid basalt model (Figs. 1,3). Documentation of these differences in initial flow characteristics and regolith protolith (Fig. 3) can enhance the understanding of the complexity of regolith development and lead in turn to a paradigm for the variation in basaltic lava flow surface and internal structure in time and space. Predictions of the forward model of lava flow emplacement can provide specific goals and objectives for further exploration of the nature and initial emplacement environment of the regolith protolith, and the evolution and current state of the resulting regolith (Tables S1-S2). Some promising areas of investigation include:

1) Analysis of orbital remote sensing data for their ability to detect and map variations in protolith/regolith parameter space (e.g., radiometry, radar, surface roughness, photometry, mineralogy, maturity indices, etc.) (Table S2). For example, Campbell et al. $(2009,2014)$ described significant variations in the distribution of decimeter-scale subsurface rocks in Maria Serenitatis, Imbrium and Crisium from Earth-based radar data, interpreted to be due to variations in initial flow properties. Bandfield et al. (2011) and Hayne et al. (2017) explored variations in regolith temperatures in a variety of enigmatic cold and hot spots detected by LRO Diviner radiometry, and Chan et al. (2010) showed multiple anomalies in microwave brightness 
temperatures in lunar mare regolith. These types of trends and anomalies could be explored for variations related to the physical properties of different regolith protoliths (Fig. 3).

2) Measurements of the vertical structure of lava flows and regolith characteristics revealed in rille, impact crater and pit crater walls could be revisited in the context of the different lava flow regolith protoliths, and in situ exploration of vertical sections (Kerber et al., 2019) should be given high priority.

3) Regolith protolith variability data may provide additional insight into regolith and underlying lava flow physical properties, thickness and internal structure relevant to past and future seismic (e.g., Cooper et al., 1974), heat flow (Langseth et al., 1976), surface and orbital ground penetrating radar (e.g., Yuan et al., 2017), and surface electrical properties data.

4) Analyzing assumptions about crater degradation processes and CSFD ages to take into account potentially varying protolith and regolith processes may help to explain the often high degree of local and regional regolith variability (e.g., Fassett and Thompson, 2014; Hirabayashi et al., 2018; Needham et al., 2018; Prieur et al., 2018).

5) Revisiting the Apollo/Luna/Chang'E data on the lunar regolith in the context of this forward-model protolith/regolith growth paradigm may provide new insights into regolith production and evolution and its variability (Lucey et al., 2006).

Examples of this array of candidate regolith protoliths (Fig. 3. Table S1) and an assessment of appropriate investigation techniques (Tables S2) provide a basis for further exploration of mare regolith diversity and geotechnical properties.

Acknowledgments. We gratefully acknowledge funding to J. W. H. for participation in the NASA Lunar Reconnaissance Orbiter Mission Lunar Orbiter Laser Altimeter (LOLA) Experiment Team (grant 80NSSC19K0605 from the National Aeronautics and Space Administration - Goddard) and from the NASA Lunar Data Analysis Program (80NSSC19K1382). L. W. thanks the Leverhulme Trust for support through an Emeritus Fellowship. We gratefully acknowledge two anonymous reviews, and independent reviews by Grant Heiken, Kaichang Di, and Christian Wohler, all of which were extremely helpful in strengthening the paper. Thanks are extended to Anne Côté for help in figure drafting and preparation. No new unpublished data were used in this research.

\section{References:}

Bandfield, J. L., Ghent, R. R., Vasavada, A. R., Paige, D. A., Lawrence, S. J., \& Robinson, M. S. (2011). Lunar surface rock abundance and regolith fines temperatures derived from LRO Diviner Radiometer data. J. Geophys. Res., 116, E0OHO2. https://doi.org/10.1029/2011JE003866

Bart, G. D. (2014). The quantitative relationship between small impact crater morphology and regolith depth. Icarus, 235, 130135. https://doi.org/ 10.1016/j.icarus.2014.03.020

Bart, G. D., Nickerson, R. D., Lawder, M. T., \& Melosh, H. J. (2011). Global survey of lunar regolith depths from LROC images. Icarus, 215, 485-490. https://doi.org/10.1016/j.icarus.2011.07.017

Campbell, B. A., B. R. Hawke, L. M. Carter, R. R. Ghent, and D. B. Campbell (2009), Rugged lava flows on the Moon revealed by Earth-based radar, Geophys. Res. Lett., 36, L22201. https://doi.org/101029/2009GL041087

Campbell, B. A., Hawke, B. R., Morgan, G. A., Carter, L. M., Campbell, D. B., \& Nolan, M. (2014). Improved discrimination of volcanic complexes, tectonic features, and regolith properties in Mare Serenitatis from Earth-based radar mapping. J. Geophys. Res. Planets, 119, 313-330. https://doi.org/10.1002/2013JE004486

Chan, K. L., Tsang, K. T., Kong, B., \& Zheng, Y.-C. (2010). Lunar regolith thermal behavior revealed by Chang'E-1 microwave brightness temperature data. Earth and Planet. Sci. Lett., 295(1-2), 287-291. https://doi.org/10.1016/j.epsl.2010.04.015 Cooper, M. R., Kovach, R. L., \& Watkins, J. S. (1974). Lunar near-surface structure. Rev. Geophys. Space Phys., 12, $291-308$. 
Delano, J. W. (1986). Pristine lunar glasses: Criteria, data and implications. Proc. Lunar Planet. Sci. Conf., 16, J. Geophys. Res., 90, D201-D213.

Di, K., Sun, S., Yue, Z., \& Liu, B. (2016). Lunar regolith thickness determination from 3D morphology of small fresh craters. Icarus, 267, 12-23. https://doi.org/10.1016/J.icarus.2015.12.013

Fassett, C. I., \& Thompson, B. J. (2014). Crater degradation on the lunar maria: Topographic diffusion and the rate of erosion on the Moon. J. Geophys. Res., 119, 2255-2271. https://doi.org/10.1002/2014/JE004698

Gaddis, L., Staid, M. I., Tyburczy, J. A., Hawke, B. R., and Petro, N. E. (2003). Compositional analyses of lunar pyroclastic deposits. Icarus, 161, 262-280.

Gaillard, F., \& Scaillet, B. (2014). A theoretical framework for volcanic degassing chemistry in a comparative planetology perspective and implications for planetary atmospheres. Earth Planet Sci Lett, 403, 307-316. https://doi.org/10.1016/j.epsl.2014.07.009

Garry, W.B., Robinson, M.S., Zimbelman, J.R., et al. (2012). The origin of Ina: Evidence for inflated lava flows on the Moon. J. Geophys. Res., 117, E00H31. doi:10.1029/ 2011JE003981.

Hamilton, C. W., Scheidt, S. P., Sori, M. M., de Wet, A. P., Bleacher, J. E., Mouginis-Mark, P., Self, S., Zimbelman, J. R., Garry, W. B., Whelley, P. L. and Crumpler. L. S. (2020). Lava-rise plateaus and inflation pits in the McCartys lava flow-field, New Mexico: An analog for pāhoehoe-like lava flows on planetary surfaces. J. Geophys. Res., 129, https://doi.org/10.1029/2019JE005975

Hauri, E. H., Weinreich, T., Saal, A. E., Rutherford, M. C., Van Orman, J. A. (2011). High pre-eruptive water contents preserved in lunar melt inclusions. Science, 333(6039), 213-215. https://doi.org/10.1126/science.1204626

Hayne, P. O., Bandfield, J. L., Siegler, M. A., Vasavada, A. R., Ghent, R. R., Williams, J.-P., et al. (2017). Global regolith thermophysical properties of the Moon from the Diviner Lunar Radiometer Experiment, J. Geophys. Res., 122, $2371-2400$. https://doi.org/10.1002/2017JE005387

Head III, J. W., \& Wilson, L. (2017). Generation, ascent and eruption of magma on the Moon: New insights into source depths, magma supply, intrusions and effusive/explosive eruptions (part 2: observations). Icarus, 283, 176-223, https://doi.org/10.1016/i.icarus.2016.05.031

Heiken, G. (1974). Petrology of Lunar Soils, Rev. Geophys. and Space Phys. 13, 567-587.

Heiken, G. and McKay, D. S. (1974). Petrography of Apollo 17 soils. Proc. Lunar Sci. Conf. 5, 843-860.

Hirabayashi, M., Howl, B. A., Fassett, C. I., Soderblom, J. M., Minton, D. A., \& Melosh, H. J. (2018). The role of breccia lenses in regolith generation from the formation of small, simple craters: Application to the Apollo 15 landing site. J. Geophys. Res., 123, 527-543, https://doi.org/10.1002/2017/JE005377

Hörz, F. (1977), Impact cratering and regolith dynamics. Phys. Chem. Earth, pp.3-15, Pergamon Press, Great Britain.

Kerber L., Denevi, B., Nesnas, I., Keszthelyi, L., Head, J. W., Pieters, C., et al. (2019). Moon Diver: A Discovery Mission concept for understanding secondary crust formation through the exploration of a lunar mare pit cross-section. Lunar Planet. Sci. Conf., 50, abstract 1163.

Keske, A. L., Clarke, A. B., and Robinson, M. R. (2020). On the eruptive origins of lunar localized pyroclastic deposits. Earth Planet. Sci. Letts., 547, 116426.

Langevin, Y., \& Arnold, J. R. (1977). The evolution of the lunar regolith, Ann. Rev. Earth Planet. Sci, 5, 449-489.

Langseth, M. G., Kheim, S. J., \& Peters, K. (1976). Revised lunar heat-flow values, Proc. Lunar Sci. Conf., 7, 3143-3171.

Lucey, P., Korotev, R. L., Gillis, J. J., Taylor, L. A., Lawrence, D., Campbell, B. A., et al. (2006). Understanding the lunar surface and space-Moon interactions. In Jolliff, B. L., M. A. Wieczorek, C. K. Shearer, C. R. Neal (Eds.), New Views of the Moon, Reviews in Mineralogy and Geochemistry, 60, pp. 83-219.

McKay, D. S., Fruland, R. M., \& Heiken, G. H. (1974). Grain size and evolution of lunar soils. Proc. Lunar Sci. Conf., 5, 887-906.

McKay, D. S., Heiken, G., Basu, A., Blanford, G., Simon, S., Reedy, R., et al. (1991). The lunar regolith. In G. H. Heiken, D. T. Vaniman, and B. M. French (Eds.), Lunar Sourcebook: A User's Guide to the Moon, pp. 285-356, Cambridge University Press, Cambridge, UK.

Morgan, C.R., Wilson, L. \& Head, J.W. (2019) Factors controlling the size distributions of lunar pyroclasts. Lunar Planet. Sci. Conf., 50, abstract 1341.

Needham, D. H., Fassett, C. I., Hirabayashi, M., \& Thomson, B. J. (2018). Local variations in lunar regolith thickness: Testing a new model of regolith formation near the Apollo 15 landing site. Lunar Planet. Sci. Conf., 49, abstract 1599.

Prieur, N. C., Rolf, T., Wünnemann, K., \& Werner, S. C. (2018). Formation of simple impact craters in layered targets: Implications for lunar crater morphology and regolith thickness. J. Geophys. Res., 123, 1555-1578. https://doi.org/10.1029/2017JE005463

Qiao, L., Head III, J. W., Wilson, L., Xiao, L., \& Dufek ,J. D. (2017). Ina pit crater on the Moon: Extrusion of waning-stage lava lake magmatic foam results in extremely young crater retention ages. Geology, 45, 455-458. https://doi.org/10.1130/G38594.1

Qiao, L., Head III, J. W., L., Xiao, L., Wilson, \& Dufek ,J. D. (2018). The role of substrate characteristics in producing anomalously young crater retention ages in volcanic deposits on the Moon: Morphology, topography, subresolution roughness, and mode of emplacement of the Sosigenes lunar irregular mare patch. Meteoritics and Planetary Science, 53, 778-812. https://doi.org/10.1111/maps.13003 
Qiao, L., Head III, J. W., Ling, Z., Wilson, L., Xiao, L., Dufek, J. D., \& Yan, J. (2019). Geological characterization of the Ina shield volcano summit pit crater on the Moon: Evidence for extrusion of waning-stage lava lake magmatic foams and anomalously young crater retention ages. J. Geophys. Res., 124, 1100-1140. https://doi.org/10.1029/2018JE005841

Qiao, L., Head, J. W., Wilson, L., \& Ling, Z. (2020). The Cauchy 5 small, low-volume lunar shield volcano: Evidence for volatile exsolution-eruption patterns and type 1/type 2 hybrid irregular mare patch formation. J. Geophys. Res., 125, https://doi.org/10.1029/2019je006171

Quaide, W. L., \& Oberbeck, V. R. (1968). Thickness determination of the lunar surface layer from lunar impact craters. J. Geophys. Res., 73, 5247-5270.

Renggli, C. J., King, P. L., Henley, R. W., \& Norman, M. D. (2017). Volcanic gas composition, metal dispersion and deposition during explosive volcanic eruptions on the Moon. Geochim Cosmochim Acta, 206, 296-311. https://doi.org/10.1016/j.gca.2017.03.012

Rutherford, M. J., Head III, J. W., Saal, A. E., Hauri, E. H., \& Wilson, L. (2017). Model for the origin, ascent and eruption of lunar picritic magmas. Am Mineral, 102, 2045-2053. https://doi.org/10.2138/am-2017-5994

Saal, A. E., Hauri, E. H., Lo Cascio, M., Van Orman, J. A., Rutherford, M. C., \& Cooper, R. F. (2008). Volatile content of lunar volcanic glasses and the presence of water in the Moon's interior. Nature, 454(7201), 192-195. https://doi.org/10.1038/nature07047

Schmitt, H. H. (1973). Apollo 17 report on the valley of Taurus-Littrow, Science, 182, 681-690.

Self, S., Thordarson, T. Keszthelyi, L., Walker, G. P. L., Hon, K., Murphy, M. T., Long, P. and Finnemore, D. (1996) A new model for the emplacement of Columbia River basalts as large, inflated pahoehoe lava flow-fields. Geophysical Research Letters, 23, 2689-2692.

Shkuratov, Y. G., \& Bondarenko, N. V. (2001). Regolith layer thickness mapping of the Moon by radar and optical data. Icarus, 149, 329-338. https://doi.org/10.1006/icar.2000.6545

Weitz, C. M., Head, J. W., Pieters, C. M. (1998). Lunar regional dark mantle deposits: Geologic, multispectral, and modeling studies. J. Geophys. Res., 103, 22,725-22,759.

Wilcox, B. B., Robinson, M. S., Thomas, P. C., \& Hawke, B. R. (2005). Constraints on the depth and variability of the lunar regolith. Meteoritics \& Planetary Science, 40, 695-710.

Wilson, L., \& Head III, J. W. (2017a). Generation, ascent and eruption of magma on the Moon: New insights into source depths, magma supply, intrusions and effusive/explosive eruptions (Part 1: Theory). Icarus, 283, 146-175. https://doi.org/10.1016/j.icarus.2015.12.039

Wilson, L., \& Head III, J. W. (2017b). Eruption of magmatic foams on the Moon: Formation in the waning stages of dike emplacement events as an explanation of "irregular mare patches". Journal of Volcanology and Geothermal Research, 335, 113-127. https://doi.org/1016/j.jvolgeores.2017.02.009

Wilson, L., \& Head III, J. W. (2018). Controls on lunar basaltic volcanic eruption structure and morphology: Gas release patterns in sequential eruption phases. Geophys Res Lett, 45, 5852-5859. https://doi.org/10.1029/2018GL078327

Wilson, L., Head III, J. W., \& Zhang, F. (2019). A theoretical model for the formation of Ring Moat Dome Structures: Products of second boiling in lunar basaltic lava flows. J Volcan Geotherm Res, 374, 160-180. https://doi.org/10.1016/j.jvolgeores.2019.02.018

Xie, M., Xiao, Z., \& Xu, A. (2018). Modeling the growth of regolith on the Moon: Implication for the evolution of crater and impactor populations. Lunar Planet. Sci. Conf., 49, abstract 1992.

Yuan, Y., Zhu, P., Zhao, N., Xiao, L., Garnero, E., Xiao, Z., et al. (2017). The 3-D geological model around Chang'E-3 landing site based on lunar penetrating radar channel 1 data. Geophys. Res. Lett., 44, 6553-6561. https://doi.org/10.1002/2017GL073589

Zhang, F., Head III, J. W., Basilevsky, A. T., Bugiolacchi, R., Komatsu, G., Wilson, L., et al. (2017). Newly discovered ring-moat dome structures in the lunar maria: Possible origins and implications. Geophys. Res. Lett., 44, 9216-9224. https://doi.org/10.1002/2017GL074416

Zhang, F., Head, J. W., Wohler, C., Bugiolacchi, R., Wilson, L,, Basilevsky, A. T., Grumpe, A. and Zhou, Y.L. (2020). Ring-Moat Dome Structures (RMDSs) in the lunar maria: Statistical, compositional, and morphological characterization and assessment of theories of origin. J. Geophys. Res., 125, e2019JE005967, doi: 10.1029/2019JE005967 
504

505

506

507

508

509

510

511
Figures:

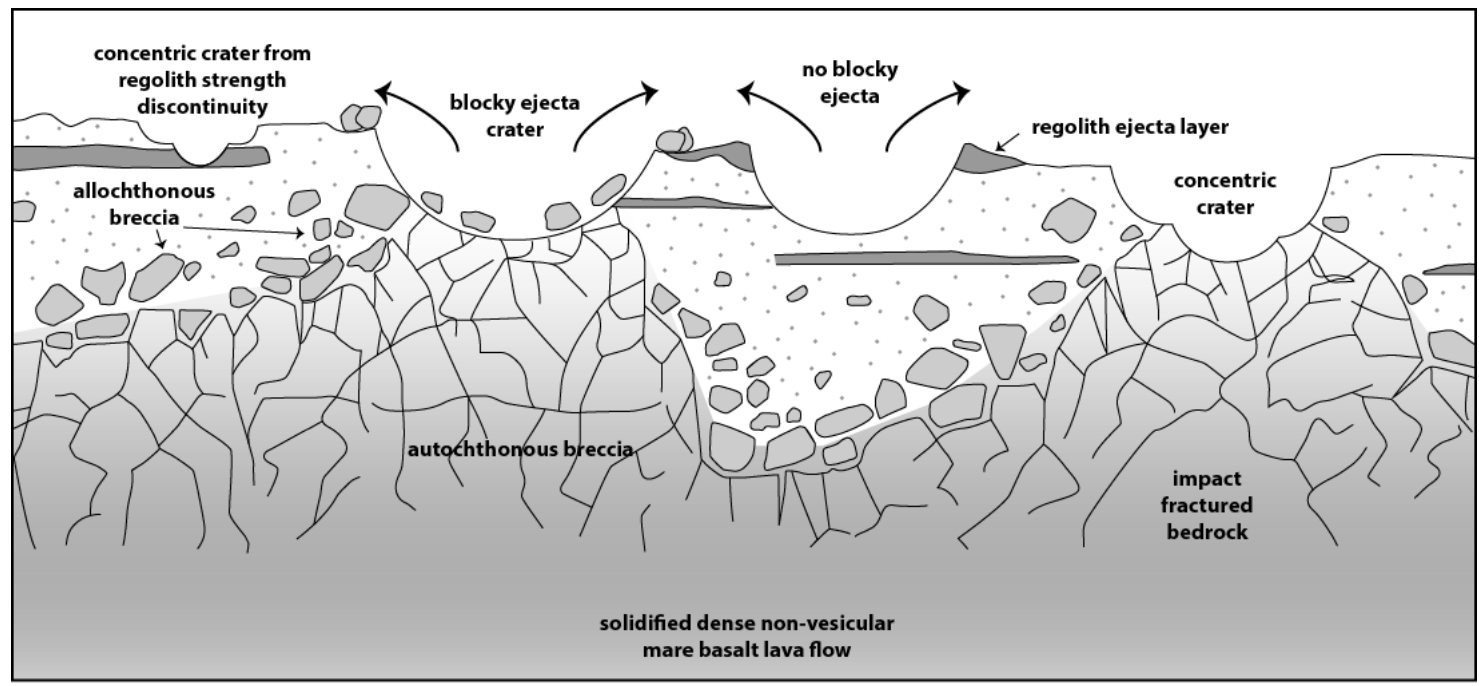

Figure 1. Traditional solid dense basalt protolith regolith evolution model (after Wilcox et al., 2005). 


\begin{tabular}{|c|c|c|c|c|}
\hline & PHASE 1 & PHASE 2 & PHASE 3 & PHASE 4 \\
\hline $\begin{array}{l}\text { Eruption } \\
\text { Phase }\end{array}$ & $\begin{array}{c}\text { Dike } \\
\text { penetrates } \\
\text { to surface, } \\
\text { transient gas } \\
\text { release } \\
\text { phase }\end{array}$ & $\begin{array}{c}\text { Dike base } \\
\text { still rising, } \\
\text { high flux } \\
\text { hawaiian } \\
\text { eruptive } \\
\text { phase }\end{array}$ & $\begin{array}{c}\text { Dike } \\
\text { equilibration, } \\
\text { lower flux } \\
\text { hawaiian to } \\
\text { strombolian } \\
\text { transition } \\
\text { phase }\end{array}$ & $\begin{array}{c}\text { Dike closing, } \\
\text { strombolian } \\
\text { vesicular } \\
\text { flow phase }\end{array}$ \\
\hline \multirow{2}{*}{$\begin{array}{c}\text { Dike } \\
\text { Configuration }\end{array}$} & Crust & & & \\
\hline & Mantle & & & \\
\hline \multirow{3}{*}{$\begin{array}{l}\text { Surface } \\
\text { Eruption } \\
\text { Style }\end{array}$} & \multirow{2}{*}{$\begin{array}{l}\text { Transparent } \\
\text { gas }\end{array}$} & \multirow{2}{*}{$\begin{array}{l}\text { Opaque pyroclastic } \\
\text { fountain }\end{array}$} & \multirow{2}{*}{$\begin{array}{c}\begin{array}{c}\text { Fountain } \\
\text { declines } \\
\text { toward } \\
\text { strombolian }\end{array}\end{array}$} & $\begin{array}{l}\text { a) Proximal } \\
\text { foam flow }\end{array}$ \\
\hline & & & & $\begin{array}{l}\text { b) Distal flow } \\
\text { inflation }\end{array}$ \\
\hline & & $\begin{array}{l}\text { Lava } \\
\text { lake }\end{array}$ & 70 & \\
\hline $\begin{array}{c}\text { Magma Rise } \\
\text { Speed }\end{array}$ & 30 to $20 \mathrm{~m} / \mathrm{s}$ & 20 to $10 \mathrm{~m} / \mathrm{s}$ & 5 to $<1 \mathrm{~m} / \mathrm{s}$ & $<1 \mathrm{~m} / \mathrm{s}$ \\
\hline $\begin{array}{c}\text { Magma } \\
\text { Volume Flux }\end{array}$ & $\sim 10^{6} \mathrm{~m}^{3} / \mathrm{s}$ & $10^{6}$ to $10^{5} \mathrm{~m}^{3} / \mathrm{s}$ & $10^{5}$ to $\sim 10^{4} \mathrm{~m}^{3} / \mathrm{s}$ & $\sim 10^{4} \mathrm{~m}^{3} / \mathrm{s}$ \\
\hline $\begin{array}{c}\text { Percent Dike } \\
\text { Volume } \\
\text { Erupted }\end{array}$ & $<5 \%$ & $\sim 80 \%$ & $\sim 5 \%$ & $\sim 10 \%$ \\
\hline $\begin{array}{c}\text { Phase } \\
\text { Duration } \\
\end{array}$ & $\sim 3$ minutes & $\sim 4$ days & $\sim 6$ days & $\sim 30$ days \\
\hline $\begin{array}{l}\text { Flow } \\
\text { Advance } \\
\text { Speed }\end{array}$ & n/a & $\sim 5$ to $0.5 \mathrm{~m} / \mathrm{s}$ & $\sim 0.2 \mathrm{~m} / \mathrm{s}$ & $\sim 0.01 \mathrm{~m} / \mathrm{s}$ \\
\hline $\begin{array}{c}\text { Flow } \\
\text { Advance } \\
\text { Distance }\end{array}$ & $n / a$ & $\sim 300 \mathrm{~km}$ & $\sim 400 \mathrm{~km}$ & $\begin{array}{c}\sim 400 \mathrm{~km} \\
\text { (flow inflates) }\end{array}$ \\
\hline $\begin{array}{c}\text { Vesicularity } \\
\text { of Lava } \\
\text { Leaving Vent }\end{array}$ & $\mathrm{n} / \mathrm{a}$ & zero & $\begin{array}{c}\text { low, but } \\
\text { increasing }\end{array}$ & very high \\
\hline
\end{tabular}

Figure 2a.

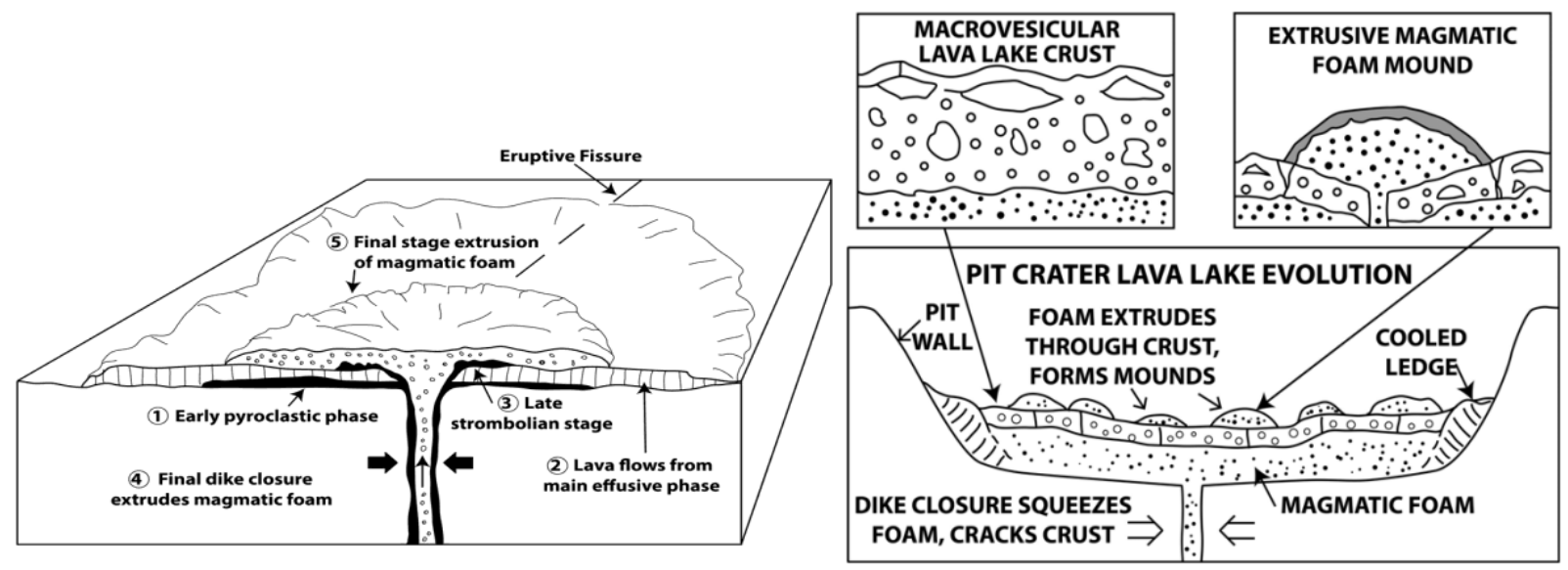

Figure $2 b$.

Figure 2c.

Figure 2. a. Four stages of a typical mare basalt eruption (after Wilson and Head, 2018). b. Vertical sequence in fissure eruption. c. Vertical sequence in pit crater eruptions. (b and c: Wilson and Head, 2017b). 


\begin{tabular}{|c|c|c|c|}
\hline $\begin{array}{c}\text { Solidified Non-Vesicular } \\
\text { Mare Basalts }\end{array}$ & Flows & $\begin{array}{l}\text { Inflated Flows: } \\
\text { Second Boiling }\end{array}$ & $\begin{array}{r}\text { Prox } \\
\text { “Auto-Reg }\end{array}$ \\
\hline $\begin{array}{l}\begin{array}{c}\text { Massive, solid, coherent, } \\
\text { generally non-vesicular } \\
\text { basalt }\end{array} \\
\begin{array}{l}\text { Cooling, solidification } \\
\text { cracks }\end{array}\end{array}$ & $\begin{array}{l}\text { Injected vesicular lava } \\
000\end{array}$ & 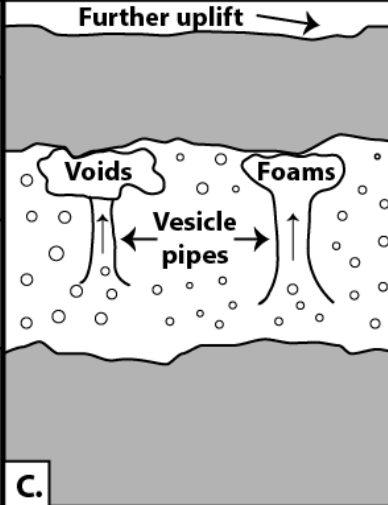 & 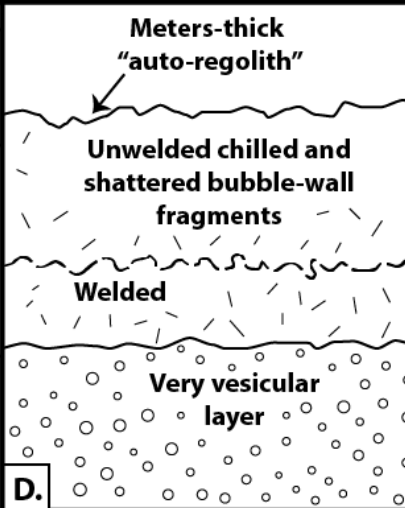 \\
\hline $\begin{array}{c}\text { Foam Flows: Coherent } \\
\text { Surfaces }\end{array}$ & Pyroclastic Deposits & $\begin{array}{l}\text { "Xenolithic"Volcanic Glass } \\
\text { Beads }\end{array}$ & $\begin{array}{l}\text { "Volcanic Pit Craters": } \\
\text { Lake Floor - Mounds }\end{array}$ \\
\hline 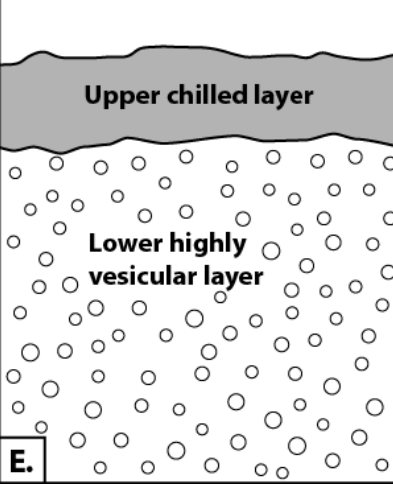 & $\begin{array}{l}\text { change with distance } \\
\text { F. }\end{array}$ & 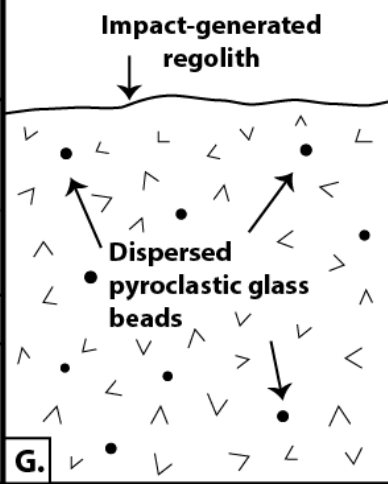 & Lava \\
\hline
\end{tabular}

Figure 3. Cross-sections of eight regolith protolith types. 
528

529

530

531

532

533

534

535

536

537

538

539

540

541

542

543

\section{Supporting Information for Geophysical Research Letters \#2020GL088334}

"Rethinking Lunar Mare Basalt Regolith Formation: New Concepts of Lava Flow Protolith and Evolution of Regolith Thickness and Internal Structure"

James W. Head ${ }^{1}$ and Lionel Wilson ${ }^{2,1}$

${ }^{1}$ Department of Earth, Environmental and Planetary Science, Brown University, Providence, Rhode Island 02912 USA.

${ }^{2}$ Lancaster Environment Centre, Lancaster University, Lancaster LA1 4YQ UK

Contents of this file: Table S1, Table S2 
Table S1: Predicted locations of the eight different regolith protolith types (Fig. 3).

A) Solidified non-vesicular mare basalts:

-General Locations: Distal parts of long fissure-fed, lava flows (Fig. 2b); medial and distal flows associated with sinuous rilles (Fig. 2a: Phase 2 distal flows).

-Specific Locations: Medial to distal parts of southwest Mare Imbrium lava flows (Schaber, 1973; Chen et al., 2018; Bugiolacchi and Guest, 2008); Apollo 11 Site (Beaty and Albee, 1978); Apollo 12 site (Neal et al., 1994); near terminations of Rima Hadley, Rima Prinz, etc. (Hurwitz et al., 2012, 2013).

\section{B) Inflated flows:}

-General Locations: Proximal to distal parts of both central vent-fed flows (Fig. 2a: Phase 4b) and long, fissure-fed lava flows (Fig. 2b) (Self et al, 1996; Hamilton et al., 2020); Possibly small irregular mare patches (IMPs) (Braden et al., 2014; Qiao et al., 2020).

-Specific Locations: Proximal and medial (Zhang et al., 2016; Chen et al., 2018) regions of SW Mare Imbrium flows; Apollo 15 site (Apollo 15 PET, 1972; Lofgren et al., 1975; Keszthelyi, 2008); Ina (Garry et al., 2012).

\section{C) Inflated flows: Second boiling:}

-General Locations: Proximal and medial parts of long, fissure-fed lava flows (Fig. 2a: Phase 4b); any areas containing ring-moat dome structures (RMDS) (Zhang et al., 2017, 2020; Wilson et al, 2019). Possibly small IMPs (Braden et al., 2014; Qiao et al., 2020).

-Specific Locations: RMDS-Central Mare Tranquillitatis, Mare Fecunditatis, Southern Oceanus Procellarum, Northern Mare Humorum (Zhang et al., 2017, 2020). IMPS-Northwestern Mare Tranquillitatis, Sechi X, Aratus D (Braden et al., 2014; Qiao et al., 2020).

\section{D) Proximal flows: "Auto-regolith" formation:}

-General Locations: Near eruption source regions (Fig. 2a: Phase 4a); fissure vents (Fig. 2b); and small shield summits (Fig. 2c), flanks.

-Specific Locations: Southwest Imbrium lava flow source regions (Zhang et al., 2016); Elongate mare source depression such as Sosigenes (Qiao et al., 2018); Cauchy 5 small shield volcano (Qiao et al., 2020); Ina Mounds (Braden et al, 2014; Qiao et al., 2019; Wilson and Head, 2017b).

\section{E) Foam flows: Coherent surfaces:}

-General Locations: Adjacent to eruption source regions (Fig. 2a: Phase 3, 4a); fissure vents (Fig. 2b); small shield summits and flanks (Fig. 2c); pit crater floors (Fig. 2c).

-Specific Locations: Flanks of Cauchy 5 small shield volcano (Qiao et al., 2020); Ina crater floor (rough unit; Garry et al., 2012; Qiao et al. 2019); Possibly regions characterized by small Irregular Mare Patches (IMPs) (see extensive lists in Braden et al., 2014 and Qiao et al., 2020).

\section{F) Pyroclastic deposits:}

-General Locations: Within regional and local dark mantle deposits (DMDs) (Fig. 2a: Phase 2, 3); associated with sinuous rilles (Fig. 2a: Phase 2). Can also be mixed with interbedded lava flows (Fig. 2a: Phase 2 proximal and medial; Fig. 2b). -Specific Locations: Regional dark mantle deposits (Aristarchus Plateau, Sinus Aestuum, Sulpicius Gallus, etc.; Gaddis et al., 1985, 2003; Weitz et al., 1998); Apollo 17 site, regional DMD interbedded with lava flows (Schmitt, 1973); Local dark mantling deposits (Alphonsus crater floor and dozens of other locations; Gaddis et al., 2000; Keske et al., 2020).

\section{G) “Xenolithic" volcanic glass beads:}

-General Locations: Virtually all lunar mare regolith soils within tens to hundreds of $\mathrm{km}$ of fissure eruption source vents (Fig. 2a: Phase 1).

-Specific Locations: Pyroclastic glass beads found in regolith and core samples from Apollo 11-17 (Delano, 1986; Heiken, 1974).

\section{H) "Volcanic Pit Craters": Lava floor-Mounds:}

-General Locations: Settings where magmatic foams can build up and extrude (Fig. 2a: Phase 3, 4); large central pit craters, shield volcano pit crater floors (Fig. 2c), elongated collapse craters (Fig. 2b).

-Specific Locations: Large irregular mare patches (Braden et al., 2014); Ina (Garry et al., 2012; Qiao et al. 2019; Wilson and Head, 2017b); Sosigenes (Qiao et al., 2018), Cauchy 5 (Qiao et al., 2020). 
601

602

603

604

605

606

607

608

609

610

611

612

613

614

615

616

617

618

619

620

621

622

623

624

625

626

627

628

629

630

631

632

633

634

635

636

637
Table S2-Remote Sensing and Related Human and Robotic Techniques for Regolith Protolith Exploration and Documentation (with selected references as examples):

\section{Orbital and Earth-Based Remote Sensing:}

1) Surface morphology, albedo, topography: Imaging systems, altimeters: (Quaide and Oberbeck, 1968; Shkuratov and Bondarenko, 2001; Wilcox et al., 2005; Lawrence et al., 2013; Bart et al.; 2011; Rosenburg et al., 2011; Kreslavsky et al., 2013; Sato et al., 2014; Bart, 2014; Di et al., 2016; Prieur et al., 2018; Qiao et al., 2019, 2020; Xie et al., 2020; Zhang et al., 2017, 2020)

2) Mineralogy and alteration: VNIR spectrometers: (Hawke et al., 1989; Weitz et al., 1998; Weitz and Head, 1999; Gaddis et al., 2003; Heather et al., 2003; Besse et al., 2011; Glotch et al., 2011)

3) Physical properties: Radiometry, thermal emission: (Banfield et al., 2011; Jin et al., 2007; Chan et al., 2010; Hayne et al., 2017; Feng et al., 2020; Meng et al., 2020; Siegler et al., 2020)

4) Near-surface/subsurface: Radar at a wide range of wavelengths and corresponding penetration depths: (Zisk et al., 1977; Peeples et al., 1978; Shkuratov and Bondarenko, 2001; Carter et al., 2009; Ono et al., 2009; Campbell et al., 2014)

\section{Surface Robotic Exploration:}

1) Surface morphology, albedo, topography: (Lunokhod, Apollo and Chang'e missions; Fa and Jen, 2007; Jin et al., 2015; Lin et al. 2020)

2) Ground penetrating radar at multiple wavelengths: (Yuan et al., 2017, 2020; Li et al., 2020)

\section{Surface Human Exploration:}

1) Astronaut operations and observations: (Apollo 11-17; representative sample of protolith rocks and derivative soils, xenolithic fragments; core tubes optimized for vertical and lateral variation of the landing region regolith; trenches and documentation of vertical stratigraphy; radial sampling of small craters to document vertical and lateral variation in the landing region; Shoemaker et al., 1969, 1970; Sutton et al., 1972; ALGIT, 1972; Ulrich et al., 1981; Wolfe et al., 1975; Schmitt, 1973; Schmitt et al., 2017)

2) Soil mechanics experiments: (Carrier, 1973; Mitchell et al., 1974)

3) Seismic, Surface Electrical Properties, Heat Flow, Gravimetry: (Talwani et al., 1973; Cooper et al., 1974; Langseth et al., 1976; Grimm, 2018; Kovach and Watkins, 1973)

\section{Laboratory Analyses:}

1) Analysis of regolith components, constituents, and relation to local bedrock and related protolith: (McKay et al., 1974; Heiken, 1974; Heiken and McKay, 1974)

2) Analysis of regolith xenoliths, material not linked to local protolth: (Delano, 1986; Xie et al., 2020)

3) Comparisons of samples from new sites with the Apollo-Luna baseline: (e.g., Chang'e 3, 4, 5: Zhao et al., 2014; Xiao et al., 2015; Huang et al., 2018; Qian et al., 2018, 2020) 
640

641

642

643

644

645

646

647

648

649

650

651

652

653

654

655

656

657

658

659

660

661

662

663

664

665

666

667

668

669

670

671

672

673

674

675

676

677

678

679

680

681

682

683

684

685

686

687

688

689

690

\section{References:}

Apollo Lunar Geology Investigation Team (1972). Geologic setting of the Apollo 15 samples, Science 175, 4070415.

Apollo 15 Preliminary Examination Team (1972). The Apollo 15 lunar samples: A preliminary description. Science 175, 363-375.

Beaty, D. W., \& Albee, A. L. (1978). Comparative petrology and possible genetic relations among the Apollo 11 basalts. Lunar and Planetary Science Conference Proceedings 9, 359-463.

Besse, S., Sunshine, J.M., Staid, M.I., Petro, N.E., Boardman, J.W., Green, R.O., Head III, J.W., Isaacson, P.J., Mustard, J.F., Pieters, C.M. (2011). Compositional variability of the Marius Hills volcanic complex from the Moon Mineralogy Mapper (M3). Journal Geophysical Research 116, E00G13, doi:10.1029/2010JE003725

Braden, S.E., Stopar, J.D., Robinson, M.S., Lawrence, S J., van der Bogert, C.H., Hiesinger, H. (2014). Evidence for basaltic volcanism on the Moon within the past 100 million years. Nature Geoscience 7, 787-791.

Bugiolacchi, R., Guest, J.E. (2008). Compositional and temporal investigation of exposed lunar basalts in the Mare Imbrium region. Icarus 197, 1-18.

Carrier, W. David (1973). Lunar soil grain size distribution. The Moon 6.3-4, 250-263.

Carter, I.M., Campbell, B.A., Hawke, B.R., Campbell, D.B., Nolan, M.C. (2009). Radar remote sensing of pyroclastic deposits in the southern Mare Serenitatis and Mare Vaporum regions of the Moon. Journal Geophysical Research 114, E11004, doi: 10.1029/2009JE003406.

Chen, Y., Li, C., Ren, X., Liu, J., Wu, Y., Lu, Y., et al. (2018). The thickness and volume of young basalts within Mare Imbrium. Journal of Geophysical Research, 123, 630-645.

https://doi.org/10.1002/2017JE005380

Fa, W., \& Jin, Y. Q. (2007). Simulation of brightness temperature from lunar surface and inversion of regolith-layer thickness. Journal of Geophysical Research: Planets, 112(E5).

Feng, J., Siegler, M. A., \& Hayne, P. O. (2020). New Constraints on Thermal and Dielectric Properties of Lunar Regolith from LRO Diviner and CE-2 Microwave Radiometer. Journal of Geophysical Research 125(1), e2019JE006130.

Gaddis L.R., Pieters, C.M., Hawke, B.R. (1985). Remote sensing of lunar pyroclastic mantling deposits. Icarus 61, 461489.

Gaddis, L.R., Hawke, B.R., Robinson, M.S., Coombs, C. (2000). Compositional analyses of small lunar pyroclastic deposits using Clementine multispectral data. Journal Geophysical Research 105(E2), 4245-4262, doi: 10.1029/1999JE001070

Glotch, T.D., Hagerty, J.J., Lucey, P.G., Hawke, B.R., Giguere, T.A., Arnold, J.A., Williams, J.P., Jolliff, B.L., Paige, D.A. (2011). The Mairan domes: Silicic volcanic constructs on the Moon. Geophysical Research Letters 38, L21204, doi: 10.1029/2011GL049548.

Grimm, R. E. (2018). New analysis of the Apollo 17 surface electrical properties experiment. Icarus, 314, $389-399$.

Hawke, B.R., Coombs, C.R., Gaddis, L.R., Lucey, P.G., Owensby, P.D. (1989). Remote sensing and geologic studies of localized dark mantle deposits on the Moon. Proc. Lunar Planet. Sci. Conf. 19, 255-268.

Heather, D. J., Dunkin, S. K., Wilson, L. (2003). Volcanism on the Marius Hills plateau: Observational analyses using 
Clementine multispectral data. Journal Geophysical Research 108, 5017, doi: 101029/2002JE001938.

Huang, J., Xiao, Z., Flahaut, J., Martinot, M., Head, J., Xiao, X., Xie, M. and Xiao, L. (2018). Geological characteristics of Von Kármán crater, northwestern south pole-Aitken Basin: Chang'E-4 landing site region. Journal of Geophysical Research 123(7), pp.1684-1700.

Hurwitz, D.M., Head, J.W., Wilson, L., Hiesinger, H. (2012). Origin of lunar sinuous rilles: Modeling effects of gravity, surface slope, and lava composition on erosion rates during the formation of Rima Prinz. Journal Geophysical Research 117, E00H14, doi:10.1029/2011JE004000.

Hurwitz, D.M., Head, J.W., Hiesinger, H. (2013). Lunar sinuous rilles: Distribution, characteristics, and implications for their origin. Planetary Space Science 79-80, 1-38, doi:10.1016/j.pss.2012.10.019

Jin, Y. Q., Xu, F., \& Fa, W. (2007). Numerical simulation of polarimetric radar pulse echoes from the lunar regolith layer with scatter inhomogeneity and rough interfaces. Radio Science, 42(03), 1-10.

Jin, W., Zhang, H., Yuan, Y., Yang, Y., Shkuratov, Y.G., Lucey, P.G., Kaydash, V.G., Zhu, M.H., Xue, B., Di, K. and Xu, B. (2015). In situ optical measurements of Chang'E-3 landing site in Mare Imbrium: 2. Photometric properties of the regolith. Geophysical Research Letters, 42(20), 8312-8319.

Kovach, R. L., \& Watkins, J. S. (1973). Apollo 17 seismic profiling: probing the lunar crust. Science, 180, 1063-1064.

Keszthelyi, L. (2008). Inflated pahoehoe at Rima Hadley. 39th Lunar and Planetary Science Conference (Abstract 2339). TX: The Woodlands.

Kreslavsky, M. A., Head, J. W., Neumann, G. A., Rosenburg, M. A., Aharonson, O., Smith, D. E., \& Zuber, M. T. (2013). Lunar topographic roughness maps from Lunar Orbiter Laser Altimeter (LOLA) data: Scale dependence and correlation with geologic features and units. Icarus 226(1), 52-66.

Lawrence, S.J., Stopar, J.D., Hawke, B.R., Greenhagen, B.T., Cahill, J.T.S., Bandfield, J.L., Jolliff, B.L., Denevi, B.W., Robinson, M.S., Glotch, T.D., Bussey, D.B.J., Spudis, P.D., Giguere, T.A., Garry, W.B. (2013). LRO observations of morphology and surface roughness of volcanic cones and lobate lava flows in the Marius Hills. Journal Geophysical Research 118, 615-634, doi: 10.1002/jgre.20060.

Li, C., Su, Y., Pettinelli, E., Xing, S., Ding, C., Liu, J., Ren, X., Lauro, S.E., Soldovieri, F., Zeng, X. and Gao, X. (2020). The Moon's farside shallow subsurface structure unveiled by Chang'E-4 Lunar Penetrating Radar. Science Advances 6, p.eaay6898.

Lin, Honglei, Yangting Lin, Wei Yang, Zhiping He, Sen Hu, Yong Wei, Rui Xu et al. (2020). New Insight Into Lunar Regolith-Forming Processes by the Lunar Rover Yutu-2." Geophysical Research Letters 47, no. 14: e2020GL087949.

Lofgren, G. E., Donaldson, C. H. and Usselman, T. M. (1975). Geology, petrology, and crystallization of Apollo 15 quartz-normative basalts, Proceedings Lunar Science Conference 6, Pergamon Press, 79-99.

Meng, Z., Chen, S., Wang, Y., Wang, T., Cai, Z., Zhang, Y., ... \& Hu, S. (2020). Reevaluating Mare Moscoviense and its vicinity using Chang'e-2 Microwave Sounder data. Remote Sensing 12(3), 535.

Mitchell, J. K., Houston, W. N., Carrier III, W. D., \& Costes, N. C. (1974). Apollo soil mechanics experiment S-200. https://ntrs.nasa.gov/citations/19740019219

Neal, C.R., Hacker, M.D., Snyder, G.A., Taylor, L.A., Liu, Y.-G. and Schmitt, R.A. (1994). Basalt generation at the Apollo 12 site, Part 1: New data, classification, and re-evaluation. Meteoritics 29, 334-348. doi:10.1111/j.1945$\underline{\text { 5100.1994.tb00597.x }}$ 
Ono, Takayuki, Atsushi Kumamoto, Hiromu Nakagawa, Yasushi Yamaguchi, Shoko Oshigami, Atsushi Yamaji, Takao Kobayashi, Yoshiya Kasahara, and Hiroshi Oya (2009). Lunar radar sounder observations of subsurface layers under the nearside maria of the Moon. Science 323, 909-912.

Peeples, W. J., Sill, W. R., May, T. W., Ward, S. H., Phillips, R. J., Jordan, R. L., ... \& Killpack, T. J. (1978). Orbital radar evidence for lunar subsurface layering in Maria Serenitatis and Crisium. Journal of Geophysical Research, 83, 34593468 .

Qian, Y.Q., Xiao, L., Zhao, S.Y., Zhao, J.N., Huang, J., Flahaut, J., Martinot, M., Head, J.W., Hiesinger, H. and Wang, G.X. (2018). Geology and scientific significance of the Rümker region in Northern Oceanus Procellarum: China's Chang'E-5 landing region. Journal of Geophysical Research 123, 1407-1430.

Qian, Y., Xiao, L., Yin, S., Zhang, M., Zhao, S., Pang, Y., Wang, J., Wang, G. and Head, J.W. (2020). The regolith properties of the Chang'e-5 landing region and the ground drilling experiments using lunar regolith simulants. Icarus 337, 113508.

Qiao, L., Head III, J. W., Ling, Z., Wilson, L., Xiao, L., Dufek, J. D., \& Yan, J. (2019). Geological characterization of the Ina shield volcano summit pit crater on the Moon: Evidence for extrusion of waning-stage lava lake magmatic foams and anomalously young crater retention ages. Journal Geophysical Research 124, 1100-1140. https://doi.org/10.1029/2018JE005841

Rosenburg, M.A., Aharonson, O., Head, J.W., Kreslavsky, M.A., Mazarico, E., Neumann, G.A., Smith, D.E., Torrence, M.H., Zuber, M.T. (2011). Global surface slopes and roughness of the Moon from the Lunar Orbiter Laser Altimeter. Journal Geophysical Research 116, doi: 10.1029/2010je003716.

Sato, H., Robinson, M. S., Hapke, B., Denevi, B. W., \& Boyd, A. K. (2014). Resolved Hapke parameter maps of the Moon. Journal of Geophysical Research 119, 1775-1805.

Schaber, G.G. (1973). Lava flows in Mare Imbrium: Geologic evaluation from Apollo orbital photography. Proceedings Lunar Planetary Science Conference 4th, 73-92.

Schmitt, H. H., Petro, N. E., Wells, R. A., Robinson, M. S., Weiss, B. P., \& Mercer, C. M. (2017). Revisiting the field geology of Taurus-Littrow. Icarus 298, 2-33.

Shoemaker, E.M., Bailey, N.G., Batson, R.M., Dahlem, D.H., Foss, T.H., Grolier, M.J., Goddard, E.N., Hait, M.H., Holt, H.E., Larson, K.B. and Rennilson, J.J. (1969). Geologic setting of the lunar samples returned by the Apollo 11 mission. NASSP, 214, 41.

Shoemaker, E.M., Batson, R.M., Bean, A.L., Conrad Jr., C., Dahlem, D.H., Goddard, E.N., Hait, M.H., Larson, K.B., Schaber, G.G., Schleicher, D.L., Sutton, R.L., Swann, G.A., Waters, A.C. (1970). Preliminary geological investigation of the Apollo 12 landing site, Part A. In: Apollo 12 Preliminary Science Report. NASA Office of Technology Utilization, Washington, D.C.

Siegler, M. A., Feng, J., Lucey, P. G., Ghent, R. R., Hayne, P. O., \& White, M. N. (2020). Lunar Titanium and Frequency-Dependent Microwave Loss Tangent as Constrained by the Chang'E-2 MRM and LRO Diviner Lunar Radiometers. Journal of Geophysical Research 125, e2020JE006405.

Sutton, R. L., Hait, M. H., \& Swann, G. A. (1972). Geology of the Apollo 14 landing site. In Lunar and Planetary Science Conference Proceedings 3, 27. 
801

802

803

804

805

806

807

808

809

810

811

812

813

814

815

816

817

818

819

820

821

822

823

824

825

826

827

828

829

830

831

832

833

834

835

Talwani, M., Thompson, G., Dent, B., Kahle, H., \& Buck, S. (1973). Traverse gravimeter results on Apollo 17. In Lunar and Planetary Science Conference 4.

Ulrich, George E., Carroll Ann Hodges, and William R. Muehlberger, eds. (1981). Geology of the Apollo 16 area, central lunar highlands. U. S. Geological Survey Professional Paper 1048. US Government Printing Office,

Weitz, C., Head, J.W. (1999). Spectral properties of the Marius Hills volcanic complex and implications for the formation of lunar domes and cones. Journal Geophysical Research 104, 18,933-18,956.

Wilson, L., Head, J., \& Zhang, F. (2019). A theoretical model for the formation of ring moat dome structures: Products of second boiling in lunar basaltic lava flows. Journal of Volcanology and Geothermal Research 374, 160180. https://doi.org/10.1016/j. jvolgeores.2019.02.018

Wolfe, E. W., Lucchitta, B. K., Reed, V. S., Ulrich, G. E., \& Sanchez, A. G. (1975). Geology of the Taurus-Littrow valley floor. Lunar and Planetary Science Conference Proceedings 6, 2463-2482.

Xiao, L., Zhu, P., Fang, G., Xiao, Z., Zou, Y., Zhao, J., ... \& Zhang, H. (2015). A young multilayered terrane of the northern Mare Imbrium revealed by Chang'E-3 mission. Science 347, 1226-1229.

Xie, M., Xiao, Z., Zhang, X., \& Xu, A. (2020). The Provenance of Regolith at the Chang'e-5 Candidate Landing Region. Journal of Geophysical Research 125, e2019JE006112.

Yuan, Y., Wang, F., Zhu, P., Xiao, L., \& Zhao, N. (2020). New constraints on the young lava flow profile in the northern Mare Imbrium. Geophysical Research Letters, e2020GL088938.

Zhao, J., Huang, J., Qiao, L., Xiao, Z., Huang, Q., Wang, J., ... \& Xiao, L. (2014). Geologic characteristics of the Chang'E-3 exploration region. Science China Physics, Mechanics and Astronomy 57, 569-576.

Zhang, F., Zhu, M. H., \& Zou, Y. L. (2016). Late stage Imbrium volcanism on the moon: Evidence for two source regions and implications for the thermal history of Mare Imbrium. Earth and Planetary Science Lettere 445, 13-27. https://doi.org/10.1016/j.epsl.2016.04.003

Zhang, F., Head, J., Basilevsky, A., Bugiolacchi, R., Komatsu, G., Wilson, L., et al. (2017). Newly discovered ring-moat dome structures in the lunar Maria: Possible origins and implications. Geophysical Research Letters 44, 9216-9224. https://doi.org/10.1002/ 2017GL074416

Zisk, S.H., Hodges, C.A., Moore, H.J., Shorthill, R.W., Thompson, T.W., Whitaker, E.A., Wilhelms, D.E. (1977). The Aristarchus-Harbinger region of the Moon: Surface geology and history from recent remote sensing observations. The Moon 17, 59-99. 